\title{
Amaranth Oil Increases Total and LDL Cholesterol Levels without Influencing Early Markers of Atherosclerosis in an Overweight and Obese Population: A Randomized Double-Blind Cross-Over Study in Comparison with Rapeseed Oil Supplementation
}

\author{
Monika Dus-Zuchowska ${ }^{1}$, Jaroslaw Walkowiak ${ }^{1, *(0)}$, Anna Morawska ${ }^{2}$, \\ Patrycja Krzyzanowska-Jankowska ${ }^{1}$, Anna Miskiewicz-Chotnicka ${ }^{1}$, Juliusz Przyslawski ${ }^{2}$ and \\ Aleksandra Lisowska ${ }^{1}$ \\ 1 Department of Pediatric Gastroenterology and Metabolic Diseases, Poznan University of Medical Sciences, \\ 60-572 Poznan, Poland; monzuchowska@gmail.com (M.D.-Z.); p.krzyzanowska81@gmail.com (P.K.-J.); \\ chotnicka@ump.edu.pl (A.M.-C.); alisowska@ump.edu.pl (A.L.) \\ 2 Department of Bromatology, Poznan University of Medical Sciences, 60-354 Poznan, Poland; \\ akm@ump.edu.pl (A.M.); jprzysla@ump.edu.pl (J.P.) \\ * Correspondence: jarwalk@ump.edu.pl; Tel.: +48-61849-1432
}

Received: 13 November 2019; Accepted: 13 December 2019; Published: 16 December 2019

\begin{abstract}
Background: Atherosclerosis (AT) is a chronic inflammatory process in which oxidative stress is the key event. Amaranth oil (AmO) has potential hypolipidemic and antiatherogenic effects. The aim of the study was to compare the effects of $\mathrm{AmO}$ and rapeseed oil $(\mathrm{RaO})$ supplementation on expression of early markers of AT and lipid profile in obese or overweight subjects. Methods: A randomized, double-blinded cross-over study was conducted, in which participants took $20 \mathrm{~mL}$ of $\mathrm{AmO}$ in the first arm and $20 \mathrm{~mL} \mathrm{RaO}$ in the second arm, switching after the washout period. Serum concentrations of adhesion molecules (sP-selectin, sVCAM-1), high-sensitivity C-reactive protein (hsCRP), asymmetric dimethylarginine (ADMA), and lipid profile were assessed before and after nutritional interventions. In addition, anthropometric parameters were measured. Results: The total (TC) and low-density lipoprotein (LDL) cholesterol concentrations increased significantly in the AmO group in comparison with $\mathrm{RaO}(\Delta \mathrm{TC} 5.52 \pm 35 \mathrm{vs}$. $-8.43 \pm 17.65 \mathrm{mg} / \mathrm{dL} ; p=0.002$ and $4.43 \pm 34.96$ vs. $-7.55 \pm 16.41 \mathrm{mg} / \mathrm{dL} ; p=0.002$, respectively). There were no significant differences in other parameters analyzed between the groups. Conclusion: The use of $\mathrm{AmO}$ instead of $\mathrm{RaO}$ may increase cardiovascular risk in obese and overweight subjects.
\end{abstract}

Keywords: atherosclerosis; amaranth oil; obesity

\section{Introduction}

The epidemic of overweight and obesity with its wide spectrum of consequences is a major public health challenge of the 21st century. It affects more than a third of the global population and is associated with more mortality than being underweight $[1,2]$. Obesity is the paramount risk factor of atherosclerosis (AT), one of the most common health problems of modern civilization. There are three stages in the onset of atherogenesis: 1 . adherence of mononuclear cells to endothelial cells; 2 . migration of mononuclear cells into the subendothelial space; and 3. differentiation and transformation of mononuclear cells into macrophages and foam cells [3]. The first stage is triggered 
by adhesion molecules, such as vascular adhesion molecule-1 (VCAM-1), intracellular adhesion molecule-1 (ICAM-1), P-selectin, and E-selectin [3-7]. The second stage requires the presence of chemoattractants in the intima, mainly monocyte chemoattractant protein (MCP-1). In the third stage, infiltrated monocytes differentiate to macrophages, absorb modified lipoproteins, mainly oxidized low-density lipoprotein (LDL), finally differentiating into foam cells [8]. These events constitute the initial steps in the development of atherosclerosis (AT). These key stages in the pathogenesis of AT are inflammatory, preceded by oxidative stress in the endothelium of blood vessels [9-11]. Proven proatherogenic agents include high-sensitive C-reactive protein (hsCRP), mainly due to its proinflammatory action, and asymmetrical dimethylarginine (ADMA), which inhibits nitric oxide production by the endothelium $[12,13]$. The dysfunction (or activation) of the endothelium as a result of high serum levels of LDL and low levels of high-density lipoprotein (HDL) is related to obesity [14]. Thus, obese subjects are more at risk of plaque formation in their blood vessels, which could lead to potentially life-threatening cardiovascular events.

A longer life expectancy has prompted scientists to broaden their knowledge regarding the causes, mechanisms, and methods of AT prevention. The improvement of socio-economic conditions and public interest in so-called functional food has created the opportunity to introduce new, healthy eating habits that can minimize the risk of AT and obesity. A novel food ingredient which provides potential health benefits is the oil from the seeds of amaranth (Amaranthus cruentus). It contains valuable fatty acids, being composed of approximately $40 \%$ linoleic acid, $32 \%$ oleic acid, and $1 \% \alpha$-linolenic acid, as well as squalene, which has potential antioxidant, antihypertensive, and hypolipemic effects. Amaranth oil (AmO) contains ten times higher amount of squalene compared with olive oil. Moreover, AmO also contains derivatives of vitamin $\mathrm{E}$ (tocopherols and tocotrienols) and phytosterols, such as spinasterol, 8-7-stigmasterol, and 8-7-ergosterol [15].

The aim of the study was to compare the effects of $\mathrm{AmO}$ versus rapeseed oil $(\mathrm{RaO})$ on novel markers of AT and the lipid profile in overweight and obese subjects. It was hypothesized that AmO would decrease the concentrations of proatherogenic agents, such as hsCRP, ADMA, adhesion molecules, and would improve lipid profile.

\section{Materials and Methods}

\subsection{Patient Characteristics}

The study enrolled 44 overweight or obese individuals, including 32 women and 12 men via written advertisements. The inclusion criteria were body mass index $(\mathrm{BMI}) \geq 25$, aged 18 years and older. The exclusion criteria involved a history of chronic systemic disease, celiac disease, liver disease, exocrine pancreatic insufficiency, current or recent (within preceding month) treatment with conjugated linoleic acid, statins, and current treatment with agents interfering with fat digestion/absorption (chitosan, orlistat, green tea). Written consent was obtained from all participants on entry into the study. Of the 51 registered subjects, 44 met the inclusion criteria of the study. A physical examination including the evaluation of body weight (BW), height, waist circumference (WC), BMI, and waist-to-hip ratio (WHR) was conducted four times: upon entry to the study, after first nutritional intervention, after washout period, and after second nutritional intervention. The study was performed in the Department of Pediatric Gastroenterology and Metabolic Diseases of Poznan University of Medical Sciences, Poland. Baseline characteristics of the study groups are presented in Table 1.

Table 1. Baseline characteristics of the study groups.

\begin{tabular}{ccc}
\hline & Mean \pm SD & $\begin{array}{c}\text { Median } \\
\text { (1st-3rd Quartile) }\end{array}$ \\
\hline Age (years) & $48.77 \pm 10.21$ & $49.00(42.00 ; 56.25)$ \\
Height $(\mathrm{cm})$ & $168.0 \pm 8.6$ & $168.3(160.0 ; 174.0)$ \\
BW $(\mathrm{kg})$ & $87.7 \pm 15.1$ & $89.8(73.4 ; 100.3)$ \\
\hline
\end{tabular}


Table 1. Cont.

\begin{tabular}{ccc}
\hline WC $(\mathrm{cm})$ & $99.2 \pm 13.3$ & $99.0(90.8 ; 108.0)$ \\
WHR & $0.89 \pm 0.08$ & $0.91(0.83 ; 0.95)$ \\
BMI $\left(\mathrm{kg} / \mathrm{m}^{2}\right)$ & $31.00 \pm 4.61$ & $30.60(27.44 ; 33.16)$ \\
hsCRP $(\mathrm{mg} / \mathrm{dL})$ & $4.59 \pm 5.64$ & $2.20(0.98 ; 4.90)$ \\
ADMA $(\mathrm{nmol} / \mathrm{L})$ & $1.36 \pm 1.15$ & $0.84(0.64 ; 1.69)$ \\
sVCAM $(\mathrm{ng} / \mathrm{mL})$ & $851.49 \pm 199.47$ & $776.80(724.43 ; 974.53)$ \\
sP-selectin $(\mathrm{ng} / \mathrm{mL})$ & $127.66 \pm 29.17$ & $125.00(11.53 ; 145.42)$ \\
TC $(\mathrm{mg} / \mathrm{dL})$ & $223.02 \pm 37.17$ & $219.00(196.00 ; 234.50)$ \\
LDL $(\mathrm{mg} / \mathrm{dL})$ & $135.62 \pm 37.99$ & $125.65(113.28 ; 153.00)$ \\
HDL $(\mathrm{mg} / \mathrm{dL})$ & $56.43 \pm 15.87$ & $53.00(43.00 ; 66.25)$ \\
TG (mg/dL) & $150.16 \pm 70.08$ & $129.50(113.25 ; 189.25)$ \\
AIP & $0.04 \pm 0.28$ & $0.07(-0.17 ; 0.22)$ \\
\hline
\end{tabular}

BW, body weight; WC, waist circumference; WHR, waist-to-hip ratio; BMI, body mass index; hsCRP, high-sensitive C-reactive protein; ADMA, assymetric dimethylarginine; sVCAM, vascular adhesion molecule-1; sP-selectin, soluble P-selectin; TC, total cholesterol; LDL, low-density cholesterol; HDL, high-density cholesterol; TG, triglycerides; AIP, Atherogenic index of plasma.

\subsection{Study Design}

The Project Was Designed as a Randomised, Double-Blind, Cross-Over Study, as Shown in the Flowchart in Figure 1.

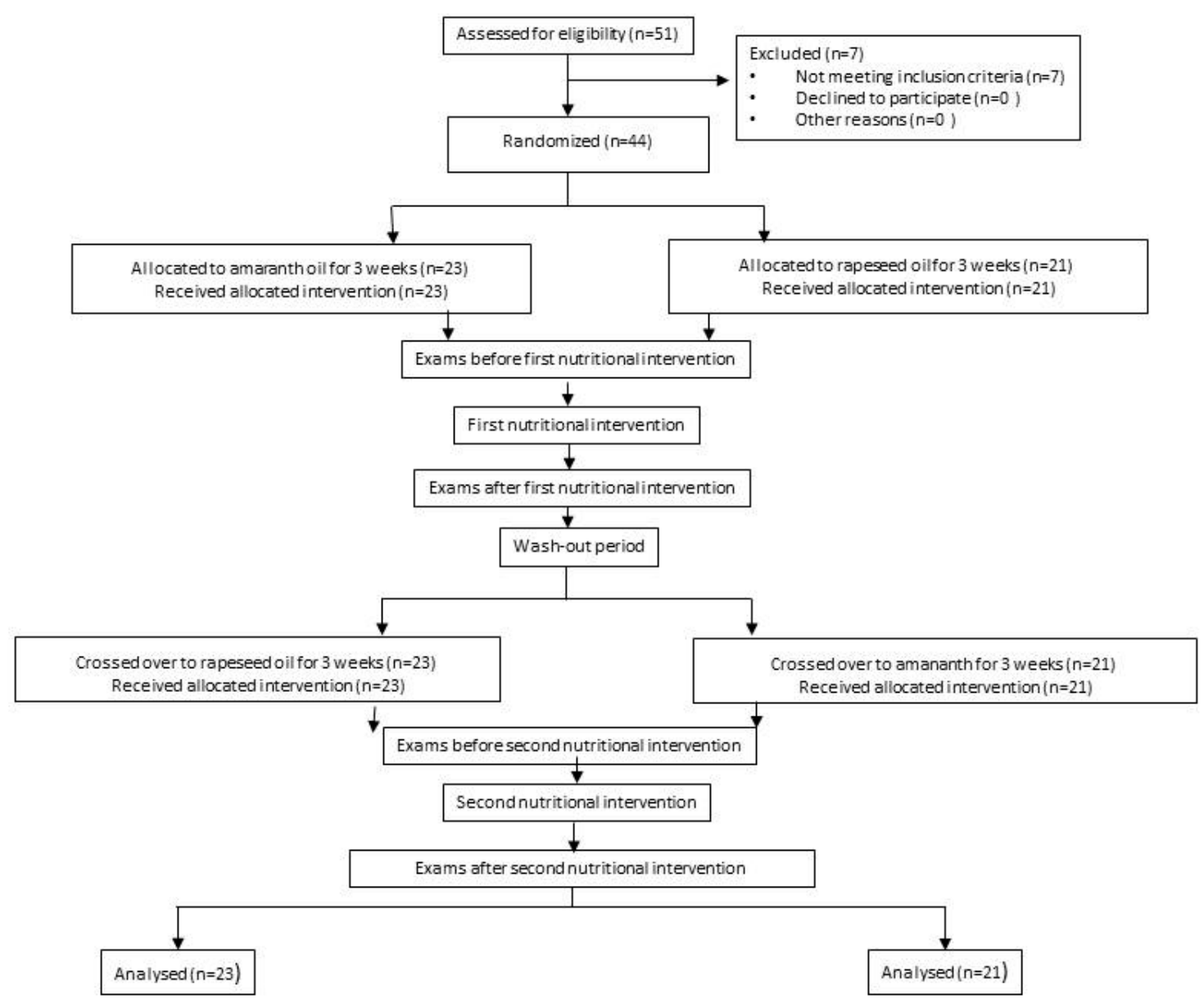

Figure 1. Study flowchart.

On entry, all participants were randomly assigned to one of the arms. In arm I, the subjects were asked to administer $20 \mathrm{~mL}$ of $\mathrm{AmO}$ per day in the first nutritional intervention and $20 \mathrm{~mL}$ of 
$\mathrm{RaO}$ per day in the second nutritional intervention; in arm II, participants received $20 \mathrm{~mL}$ of $\mathrm{RaO}$ per day in the first nutritional intervention and $20 \mathrm{~mL}$ of AmO per day in the second nutritional intervention. The first and second nutritional interventions were separated by a three-week washout period. The investigators and participants were blinded from the computer-generated randomization codes until the end of all data analysis.

The AmO used in the study was extracted from Amaranthus cruentus and given in the form of $\mathrm{Ol}^{\prime}$ Amar-dietary supplement produced by "Szarlat", Lomza, Poland. The RaO used in the study was produced by VITACORN, Poznan, Poland. Both oils were stored in identical bottles. Neither patients nor research staff knew the content of the bottles. Doses of oil were applied in exchange for $20 \mathrm{~g}$ of fat used in the diet, so that the energy value of the diet did not change during the study. The basic characteristics of the diet are presented in Table 2.

Table 2. Diet analysis of enrolled patients.

\begin{tabular}{ccc}
\hline \multirow{2}{*}{ Analyzed Basic Nutrients } & \multicolumn{2}{c}{ Patients $(\boldsymbol{n}=\mathbf{4 4})$} \\
\cline { 2 - 3 } & Mean \pm SD & Median (1st-3rd Quartile) \\
\hline Energy [kcal] & $2153 \pm 656$ & $2072(1642 ; 6870)$ \\
Energy from fats (\%) & $37.6 \pm 6.7$ & $35.7(32.9 ; 42.2)$ \\
Energy from protein (\%) & $15.3 \pm 2.4$ & $15.4(13.9 ; 16.7)$ \\
Energy from carbohydrates (\%) & $47.1 \pm 7.2$ & $47.5(42.2 ; 52.9)$ \\
Protein (g) & $80.2 \pm 21.3$ & $78.8(64.6 ; 93.4)$ \\
Fat (g) & $89.8 \pm 21.3$ & $85.9(72.5 ; 102.5)$ \\
Cholesterol (mg) & $331 \pm 128$ & $316(235 ; 391)$ \\
SFA (g) & $28.8 \pm 11.9$ & $27.1(20.6 ; 35.1)$ \\
MUFA (g) & $38.7 \pm 13.5$ & $37.1(31.2 ; 43.3)$ \\
PUFA (g) & $15.9 \pm 4.6$ & $15.1(12.9 ; 19.0)$ \\
Carbohydrates (g) & $262.6 \pm 81.6$ & $259.1(197.3 ; 312.9)$ \\
\hline
\end{tabular}

SFA, saturated fatty acids; MUFA, mono-unsaturated fatty acids; PUFA, polyunsaturated fatty acids.

At the end of each stage of the trial, anthropometric measurements and blood samples were collected from every participant. Throughout the whole period of the study, participants remained under the control of the dietician, who supervised the proper course of nutritional intervention and kept regular telephone contact to check compliance to the protocol, correctness and regularity in the administration of the appropriate oil. All study participants maintained their current lifestyle, including eating habits and physical activity during the whole study period.

\subsection{Biochemical Analysis}

A venous blood sample $(7.5 \mathrm{~mL})$ was collected according to standard methods following an overnight fast and was centrifuged immediately. The plasma was collected in a tube and stored at $-70{ }^{\circ} \mathrm{C}$ until analysis. In all study participants, the following parameters related to the prediction of atherosclerosis risk were assessed: soluble P-selectin (sP-selectin: Human P-selectin/CD62P ELISA Kit, R\&D Systems, Minneapolis, MN, USA) and VCAM-1 (sVCAM-1: Human sVCAM-1 Quantikine ELISA Kit; R\&D Systems, Minneapolis, MN, USA); ADMA (quantitative ELISA test, BioVendor, R\&D Systems, Minneapolis, MN, USA); hsCRP (ELISA method, ELISA Kit Oxis, International Inc., Foster City, CA, USA), lipid profile (total cholesterol (TC), triglycerides (TG), HDL, LDL—enzymatic colorimetric method, Biomerieux Poland, Warsaw, Poland). Additionally, the Atherogenic Index of Plasma (AIP), defined as $\log (\mathrm{TG} / \mathrm{HDL})$, was calculated for every subject before and after every nutritional intervention.

\subsection{Statistics}

Statistical analysis was performed using STATISTICA 12 software packages (StatSoft Inc., Tulsa, OK, USA). The Shapiro-Wilk test was used to assess the normality distribution of quantitative variables. 
The changes of values (deltas $[\Delta]$ ) for anthropometric and biochemical parameters before and after nutritional intervention were calculated. The results are presented as mean \pm standard deviation (SD) and medians with interquartile ranges. The statistical significance of differences in deltas of the parameters between the groups ( $\mathrm{AmO}$ vs. $\mathrm{RaO}$ ) were determined with the use of the Wilcoxon signed-rank test. The significance level was set at $p<0.05$.

Assuming the probability of a type-I error at an alpha cut-off level of $5 \%(0.05)$, the probability of a type-II error at a beta cut-off level of $20 \%(0.2)$, the difference of anticipated means equal to $20 \%$, the expected value of standard deviation equal to $30 \%$ of the mean, and the enrolment ratio equal to 1 , the sample size was estimated at 35 . Anticipating a maximum $20 \%$ drop out rate, 44 patients were recruited.

The primary outcome was defined as differences in changes of high-sensitive C-reactive protein (hsCRP) concentration between the $\mathrm{AmO}$ and $\mathrm{RaO}$ group. The secondary outcomes were established as differences in changes of novel markers of atherosclerosis (ADMA, sP-selectin, vascular adhesion molecule-1 (sVCAM)) and lipid profile between the groups studied. In addition, the anthropometric parameters were assessed and compared between $\mathrm{AmO}$ and $\mathrm{RaO}$ groups.

This study was designed in accordance with the guidelines from the Declaration of Helsinki, and all procedures involving human beings were approved by the local Bioethics Committee of the Institutional Review Board at the Poznan University of Medical Sciences, Poland (approval number 359/14). Written informed consent was obtained from all participants. The trial was registered in the German Clinical Trials Register (DRKS-ID: DRKS00014046; URL: https://www.germanctr.de/).

The project was awarded a research grant from the NUTRICIA Foundation (number RG2/2017). The idea, design, analysis, and presentation of study results in this article were not influenced by the NUTRICIA Foundation.

\section{Results}

Of the 55 potential participants, 44 entered the study and were randomly assigned for cross-over, including 23 patients from the $\mathrm{AmO}$ to the $\mathrm{RaO}$ and 21 patients from the $\mathrm{RaO}$ to $\mathrm{AmO}$. None of the participants withdrew, and no one was excluded during the course of the study.

\subsection{Anthropometric Parameters}

The differences in changes of values $(\Delta)$ for anthropometric parameters between groups are presented in Table 3. There were no significant differences between changes of BW, height, WC, WHR, and BMI between the groups studied.

Table 3. Differences in the changes of values $(\Delta)$ for anthropometric parameters between groups supplemented with $\mathrm{AmO}$ and $\mathrm{RaO}$.

\begin{tabular}{|c|c|c|c|c|c|}
\hline \multirow[b]{2}{*}{$\Delta$} & \multicolumn{2}{|c|}{$\mathrm{AmO}$} & \multicolumn{2}{|r|}{$\mathrm{RaO}$} & \multirow{2}{*}{$p$-Value } \\
\hline & Mean \pm SD & $\begin{array}{c}\text { Median } \\
\text { (1st-3rd Quartile) }\end{array}$ & Mean \pm SD & $\begin{array}{c}\text { Median } \\
\text { (1st-3rd Quartile) }\end{array}$ & \\
\hline BW (kg) & $-0.2 \pm 1.3$ & $-0.1(-0.7 ; 0.5)$ & $0.0 \pm 1.6$ & $0.1(-0.5 ; 0.8)$ & 0.274 \\
\hline $\mathrm{WC}(\mathrm{cm})$ & $-0.9 \pm 3.7$ & $-1.0(-4.0 ; 1.3)$ & $-0.4 \pm 3.1$ & $0.0(-2.0 ; 2.0)$ & 0.484 \\
\hline WHR & $0.00 \pm 0.03$ & $0.00(-0.02 ; 0.03)$ & $0.00 \pm 0.03$ & $0.00(-0.03 ; 0.02)$ & 0.882 \\
\hline BMI $\left(\mathrm{kg} / \mathrm{m}^{2}\right)$ & $0.07 \pm 0.47$ & $-0.04(-0.24 ; 0.17)$ & $0.01 \pm 0.56$ & $0.04(-0.19 ; 0.27)$ & 0.232 \\
\hline
\end{tabular}

$\mathrm{AmO}$, amaranth oil; $\mathrm{RaO}$, rapeseed oil; $\mathrm{BW}$, body weight; WC, waist circumference; WHR, waist-to-hip ratio; BMI, body mass index. 


\subsection{Biochemical Parameters}

\subsection{1. hsCRP}

There were no significant differences in changes of hsCRP concentration ( $\triangle$ hsCRP) between AmO and $\mathrm{RaO}$ groups, as shown in Table 4.

Table 4. Differences in the changes of hsCRP concentration ( $\triangle \mathrm{hsCRP}$ ) between $\mathrm{AmO}$ and $\mathrm{RaO}$ groups.

\begin{tabular}{|c|c|c|c|c|c|}
\hline \multirow[b]{2}{*}{$\Delta$} & \multicolumn{2}{|c|}{ Amo } & \multicolumn{2}{|r|}{$\mathrm{RaO}$} & \multirow{2}{*}{$p$-Value } \\
\hline & Mean \pm SD & $\begin{array}{c}\text { Median } \\
\text { (1st-3rd Quartile) }\end{array}$ & Mean \pm SD & $\begin{array}{c}\text { Median } \\
\text { (1st-3rd Quartile) }\end{array}$ & \\
\hline hsCRP (mg/dL) & $0.18 \pm 3.03$ & $0.15(-0.43 ; 0.75)$ & $-0.32 \pm 4.99$ & $0.00(-0.73 ; 1.30)$ & 0.554 \\
\hline ADMA (nmol/L) & $-0.01 \pm 0.34$ & $0.00(-0.17 ; 0.10)$ & $0.08 \pm 0.41$ & $0.06(-0.02 ; 0.25)$ & 0.135 \\
\hline sVCAM (ng/mL) & $-9.12 \pm 127.94$ & $4.45(-103.78 ; 57.58)$ & $-50.83 \pm 128.03$ & $-62.95(-112.73 ; 7.20)$ & 0.107 \\
\hline sP-selectin (ng/mL) & $-2.51 \pm 19.05$ & $-3.2(-17.29 ; 9.63)$ & $-2.11 \pm 19.78$ & $-5.36(-15.30 ; 10.62)$ & 0.616 \\
\hline
\end{tabular}

$\mathrm{AmO}$, amaranth oil; $\mathrm{RaO}$, rapeseed oil; hsCRP, high-sensitive C-reactive protein; $\mathrm{ADMA}$, assymetric dimethylarginine; sVCAM, vascular adhesion molecule-1; sP-selectin, soluble P-selectin.

\subsubsection{Novel Markers of AT}

There were no significant differences in changes of ADMA, sVCAM, and sP-Selectin ( $\triangle A D M A$, $\triangle$ sVCAM, and $\Delta$ sP-Selectin, respectively) between the $\mathrm{AmO}$ and $\mathrm{RaO}$ groups, as presented in Table 4.

\subsubsection{Lipid Profile}

The differences in changes of TC, LDL, HDL, triglycerides (TG), and AIP ( $\triangle \mathrm{TC}, \Delta \mathrm{LDL}, \Delta \mathrm{HDL}$, $\Delta \mathrm{TG}$ and $\triangle \mathrm{AIP}$, respectively) between $\mathrm{AmO}$ and $\mathrm{RaO}$ groups are presented in Table 5 . The TC and LDL concentrations increased significantly in $\mathrm{AmO}$ group in comparison with $\mathrm{RaO}$, with no significant differences in HDL and TG changes between groups.

Table 5. Differences in changes of TC, LDL, HDL, and TG ( $\Delta \mathrm{TC}, \Delta \mathrm{LDL}, \Delta \mathrm{HDL}$ and $\Delta \mathrm{TG}$ respectively) between the $\mathrm{AmO}$ and $\mathrm{RaO}$ groups.

\begin{tabular}{cccccc}
\hline \multirow{2}{*}{$\boldsymbol{\Delta}$} & \multicolumn{2}{c}{ AmO } & \multicolumn{2}{c}{ RaO } & \\
\cline { 2 - 5 } & Mean \pm SD & $\begin{array}{c}\text { Median } \\
\text { (1st-3rd Quartile) }\end{array}$ & Mean \pm SD & $\begin{array}{c}\text { Median } \\
\text { (1st-3rd Quartile) }\end{array}$ & \\
\hline TC (mg/dL) & $5.52 \pm 35.61$ & $11.00(-8.25 ; 26.00)$ & $-8.43 \pm 17.65$ & $-5.00(-20.25 ; 5.25)$ & 0.002 \\
LDL (mg/dL) & $4.43 \pm 34.96$ & $11.20(-8.2 ; 20.7)$ & $-7.55 \pm 16.41$ & $-7.2(-17.00 ; 4.03)$ & 0.002 \\
HDL (mg/dL) & $0.54 \pm 6.26$ & $0.50(-3.25 ; 5.00)$ & $-0.65 \pm 6.81$ & $0.00(-5.00 ; 4.25)$ & 0.805 \\
TG (mg/dL) & $7.43 \pm 62.96$ & $0.50(-21.25 ; 23.25)$ & $1.39 \pm 51.66$ & $-1.00(-28.75 ; 29.25)$ & 0.788 \\
AIP & $0.01 \pm 0.15$ & $-0.02(-0.09 ; 0.08)$ & $0.00 \pm 0.21$ & $-0.28(-0.15 ; 0.10)$ & 0.427 \\
\hline
\end{tabular}

TC, total cholesterol; LDL, low-density cholesterol; HDL, high-density cholesterol; TG, triglycerides; AIP, Atherogenic Index of Plasma.

\section{Discussion}

Our study was designed to assess the potential antiatherogenic effect of AmO supplementation in a Central European population of obese and overweight subjects. To the best of our knowledge, it is the first trial to analyze the impact of amaranth oil on concentrations of novel markers of AT in comparison with rapeseed oil supplementation.

The strength of this study was its randomized, double-blinded design and analysis of new markers of AT. The cross-over design removed the "patient effect", thereby reducing variability and increasing the precision of estimation. To diminish the carryover effect, the washout period was incorporated to the study design. All the participants finished both nutritional interventions. The limitation of the study was that more women than men participated. The hypertension was not the exclusion criterion due to its widespread occurrence. Few of the patients took hypotensive drugs during the 
study. Although the hypotensive drugs may interfere the lipid profile, in our project the use of the drugs remained unchanged during the whole period of the study. Moreover, the study was designed as a cross-over trial to remove potential "patient effect".

The primary outcome of the study, the differences in changes of hsCRP concentration between the $\mathrm{AmO}$ and $\mathrm{RaO}$ groups, reflected the inflammatory status, the paramount event in atherogenic plaque formation [11]. According to the American Heart Association, levels over $3 \mathrm{mg} / \mathrm{dL}$ signify increased cardiovascular risk. Hs-CRP directly participates in atherogenesis by modulating endothelial function via expression of adhesion molecules, selectins, and MCP-1 [13,16]. In our study, we did not find any significant difference between changes of hsCRP in the $\mathrm{AmO}$ and $\mathrm{RaO}$ groups. As the amaranth oil contains high amounts of plant lignans, known for their anti-inflammatory properties [17], we expected a decrease in hsCRP in the group supplemented with amaranth oil. To date, there has only been one study describing the impact of amaranth on hsCRP level in the literature. Kabiri et al. reported a decrease in CRP concentration in rabbits fed a cholesterol-rich diet supplemented with extracts of Amaranthus caudatus [18]. The discrepancy between the results of Kabiri and our study could be explained by differences in the form (extracts versus oil) and species of the used plant. Furthermore, the study of Kabiri was carried out on animals.

The secondary study outcome focused on the novel markers of AT and lipid status of the participants. This was the first trial to assess the impact of AmO vs. RaO supplementation on adhesion molecules and ADMA concentrations. ADMA is an endogenous inhibitor of endothelial nitric oxide synthase (eNOS), which is thought to be directly implicated in the regulation of the vascular redox state in human AT by affecting superoxide generation and NO bioavailability [19]. As ADMA reflects the endothelial status and adhesion molecules play a key role in atherogenesis process [20,21], we hypothesized that AmO supplementation would affect their concentrations in comparison to $\mathrm{RaO}$. However, the results of our study did not support this hypothesis, but AmO supplementation significantly affected the lipid profile. Interestingly, the TC and LDL increased significantly in the AmO group in comparison with the RaO group, but there were no significant differences in changes of HDL and TG between the two groups. The increase of TC and LDL was unexpected. In the literature, most authors attribute the hypolipemic properties of AmO to high levels of squalene, the substance involved in cholesterol synthesis [22]. Qureshi and co-workers studied the influence of amaranth intake on cholesterogenesis in chickens, showing that serum TC and LDL were lowered by $10 \%-30 \%$ and $7 \%-70 \%$, respectively, in birds fed amaranth-containing diets [23]. Also, it was observed that hamsters receiving a hypercholesterolemic diet supplemented with amaranth oil had serum levels of TC and non-HDL decreased by $15 \%$ and $22 \%$, respectively, in comparison with the control group [24]. Although most studies regarding the effect of AmO on lipid profile were designed using animal models, so far there was one study in humans, performed by Martirosyan and co-workers [25]. They investigated the effects of AmO in patients suffering from coronary heart disease and hypertension with obesity, showing that AmO supplementation decreased significantly TC, TG, LDL, and VLDL. Although the study was a large, randomized placebo-controlled trial, they used a different type of AmO (Amaranthus hybridus L. vs. Amaranthus cruentus) as well as different dose (6-12-18 mL/per day vs. $20 \mathrm{~mL} /$ per day) in comparison with our study. Interestingly, the diet used by Martyrosyan et al. was a lower-energy diet $(1600 \mathrm{kcal}$ vs. $2154 \mathrm{kcal})$ and contained lower amounts of fat $(18 \%$ vs. $38 \%)$, both of which could affect the results. Nonetheless, our results agree with two studies. De Castro and co-workers demonstrated that $\mathrm{AmO}$, and its component squalene, did not exert a hypocholesterolemic effect in hamsters fed a diet containing high amounts of saturated fat and cholesterol [26]. Miettinen et al. reported that dietary $\mathrm{RaO}$ supplementation reduced serum LDL cholesterol by 10\% from initial values during a 6 week baseline period, but addition of $1 \mathrm{~g}$ squalene to rapeseed oil for 9 weeks resulted in increases of serum TC, VLDL, IDL, and LDL concentrations by $12 \%, 34 \%, 28 \%$, and $12 \%$, respectively [27]. Furthermore, $\mathrm{AmO}$ is rich in palmitic acid (20.4\% in $\mathrm{AmO}$ vs. $3.6 \%$ in $\mathrm{RaO})$, which is associated with an increased risk of coronary heart disease [28]. However, Clandinin et al. indicated that palmitic acid has no effect on serum lipoprotein profiles in the presence of recommended intakes for 18:2n-6 acids [29]. 
As AIP is a strong marker to predict the risk of AT and coronary heart disease [30-32], we assessed the aforementioned parameter. According to the calculated value, patients can be qualified to the group of low, intermediate, or high risk. The baseline AIP mean and median were low, and the differences in changes of AIP between the groups were not significant. The results corresponded with outcomes of HDL and TG changes between the groups.

Finally, the search for genetic determinants of differences in response to nutritional interventions in inhabitants of different regions requires further exploration. In a recent study, Lankinen et al. reported that the inflammatory response to dietary linoleic acid depends on genotype [33]. In our previous study, we compared the impact of Mediterranean diet and Central European diet on the markers of AT, the authors showed the effects of Mediterranean diet do not exceed Central European Diet in a Central European population [34]. In the past, amaranth together with beans and maize were a staple of the native Central American diet [23]. According to climate changes and the need to identify new species that can be grown in drought conditions, amaranth was brought to Europe as a promising substitute crop [35]. However, we assume, it may require an unspecified period of time to adapt the metabolomic and genomic profiles of the population to routine consumption of new nutrients.

\section{Conclusions}

In conclusion, the use of $\mathrm{AmO}$ instead of $\mathrm{RaO}$ may promote a proatherogenic lipid profile in obese and overweight inhabitants. However, whether this effect is limited to Central European inhabitants remains to be elucidated, therefore, regional differences in response to nutritional interventions should be focus of further research.

Author Contributions: Conceptualization, M.D.-Z., J.W., J.P., A.L.; methodology, M.D.-Z., J.W., A.M., P.K.-J., A.M.-C., J.P., A.L.; investigation, M.D.-Z., J.W., A.M., P.K.-J., A.M.-C., A.L.; data curation, M.D.-Z., J.W., A.M., J.P., A.L.; writing-original draft preparation, M.D.-Z., A.L.; writing-review and editing J.W., A.M., P.K.-J., A.M.-C., J.P.; project administration, A.L.; funding acquisition, A.L.

Funding: This research was funded by NUTRICIA Foundation, grant number RG2/2017.

Conflicts of Interest: M.D.-Z. reports personal fees and nonfinancial support from Nestle, Recordati, and Nutricia. J.W. reports personal fees and nonfinancial support from Biocodex, BGP Products, Chiesi, Hipp, Humana, Mead Johnson Nutrition, Merck Sharp \& Dohme, Nestle, Nutricia, Roche, Sequoia Pharmaceuticals, and Vitis Pharma, outside the submitted work, and also grant and personal fees from Norsa Pharma and Nutricia Research Foundation Poland, also outside the submitted work. P.K.-J. \& J.P. declare no conflict of interest. A.L. reports personal fees from Norsa Pharma and grant from Nutricia Research Foundation Poland, outside the submitted work. The funders had no role in the design of the study; in the collection, analyses, or interpretation of data; in the writing of the manuscript, or in the decision to publish the results.

\section{References}

1. Hruby, A.; Hu, F.B. The Epidemiology of Obesity: A Big Picture. Pharmacoeconomics 2015, 33, $673-689$. [CrossRef] [PubMed]

2. Stevens, G.A.; Singh, G.M.; Lu, Y.; Danaei, G.; Lin, J.K.; Finucane, M.M.; Bahalim, A.N.; McIntire, R.K.; Gutierrez, H.R.; Cowan, M.; et al. National, regional, and global trends in adult overweight and obesity prevalences. Popul. Health Metr. 2012, 10, 22. [CrossRef] [PubMed]

3. Fan, J.; Watanabe, T. Inflammatory reactions in the pathogenesis of atherosclerosis. J. Atheroscler. Thromb. 2003, 10, 63-71. [CrossRef] [PubMed]

4. Cybulsky, M.I.; Gimbrone, M.A. Endothelial expression of a mononuclear leukocyte adhesion molecule during atherogenesis. Science 1991, 251, 788-791. [CrossRef] [PubMed]

5. Nie, Q.; Fan, J.; Haraoka, S.; Shimokama, T.; Watanabe, T. Inhibition of mononuclear cell recruitment in aortic intima by treatment with anti-ICAM-1 and anti-LFA-1 monoclonal antibodies in hypercholesterolemic rats: Implications of the ICAM-1 and LFA-1 pathway in atherogenesis. Lab. Investig. 1997, 77, 469-482. [PubMed]

6. Dong, Z.M.; Chapman, S.M.; Brown, A.A.; Frenette, P.S.; Hynes, R.O.; Wagner, D.D. The combined role of Pand E-selectins in atherosclerosis. J. Clin. Investig. 1998, 102, 145-152. [CrossRef] 
7. Nakashima, Y.; Raines, E.W.; Plump, A.S.; Breslow, J.L.; Ross, R. Upregulation of VCAM-1 and ICAM-1 at atherosclerosis-prone sites on the endothelium in the ApoE-deficient mouse. Arter. Thromb. Vasc. Biol. 1998, 18, 842-851. [CrossRef]

8. Johnson, J.L.; Newby, A.C. Macrophage heterogeneity in atherosclerotic plaques. Curr. Opin. Lipidol. 2009, 20, 370-378. [CrossRef]

9. Fruchart, J.-C.; Nierman, M.C.; Stroes, E.S.G.; Kastelein, J.J.P.; Duriez, P. New risk factors for atherosclerosis and patient risk assessment. Circulation 2004, 109, III15-III19. [CrossRef]

10. Mao, Y.; Qi, X.; Xu, W.; Song, H.; Xu, M.; Ma, W.; Zhou, L. Serum gamma-glutamyl transferase: A novel biomarker for coronary artery disease. Med. Sci. Monit. 2014, 20, 706-710.

11. Ross, R. Atherosclerosis-An inflammatory disease. N. Engl. J. Med. 1999, 340, 115-126. [CrossRef] [PubMed]

12. De Gennaro Colonna, V.; Bianchi, M.; Pascale, V.; Ferrario, P.; Morelli, F.; Pascale, W.; Tomasoni, L.; Turiel, M. Asymmetric dimethylarginine (ADMA): An endogenous inhibitor of nitric oxide synthase and a novel cardiovascular risk molecule. Med. Sci. Monit. 2009, 15, RA91-RA101. [PubMed]

13. Lau, D.C.W.; Dhillon, B.; Yan, H.; Szmitko, P.E.; Verma, S. Adipokines: Molecular links between obesity and atheroslcerosis. Am. J. Physiol. Heart Circ. Physiol. 2005, 288, H2031-H2041. [CrossRef] [PubMed]

14. Boden, W.E. High-density lipoprotein cholesterol as an independent risk factor in cardiovascular disease: Assessing the data from Framingham to the Veterans Affairs High-Density Lipoprotein Intervention Trial. Am. J. Cardiol. 2000, 86, 19L-22L. [CrossRef]

15. Kaźmierczak, A.; Bolesławska, I.; Przysławski, J. Amaranth-Its use in the prevention and treatment of certain civilization-related diseases. Now. Lek. 2011, 80, 192-198.

16. Bălăşoiu, M.; Bălăşoiu, A.T.; Stepan, A.E.; Dinescu, S.N.; Avrămescu, C.S.; Dumitrescu, D.; Cernea, D.; Alexandru, D. Proatherogenic adipocytokines levels in metabolic syndrome. Rom. J. Morphol. Embryol. 2014, 55, 29-33.

17. Spilioti, E.; Holmbom, B.; Papavassiliou, A.G.; Moutsatsou, P. Lignans 7-hydroxymatairesinol and 7-hydroxymatairesinol 2 exhibit anti-inflammatory activity in human aortic endothelial cells. Mol. Nutr. Food Res. 2014, 58, 749-759. [CrossRef]

18. Kabiri, N.; Asgary, S.; Setorki, M. Lipid lowering by hydroalcoholic extracts of Amaranthus caudatus L. induces regression of rabbits atherosclerotic lesions. Lipids Health Dis. 2011, 10, 89. [CrossRef]

19. Antoniades, C.; Shirodaria, C.; Leeson, P.; Antonopoulos, A.; Warrick, N.; Van-Assche, T.; Cunnington, C.; Tousoulis, D.; Pillai, R.; Ratnatunga, C.; et al. Association of plasma asymmetrical dimethylarginine (ADMA) with elevated vascular superoxide production and endothelial nitric oxide synthase uncoupling: Implications for endothelial function in human atherosclerosis. Eur. Heart J. 2009, 30, 1142-1150. [CrossRef]

20. Mels, C.M.C.; Schutte, A.E.; Huisman, H.W.; Smith, W.; Kruger, R.; van Rooyen, J.M.; Schwedhelm, E.; Atzler, D.; Böger, R.H.; Malan, N.T.; et al. Asymmetric dimethylarginine and symmetric dimethylarginine prospectively relates to carotid wall thickening in black men: The SABPA study. Amino Acids 2017, 49, 1843-1853. [CrossRef]

21. Böger, R.H. Asymmetric dimethylarginine (ADMA): A novel risk marker in cardiovascular medicine and beyond. Ann. Med. 2006, 38, 126-136. [CrossRef] [PubMed]

22. Chaturvedi, A.; Sarojini, G.; Devi, N.L. Hypocholesterolemic effect of amaranth seeds (Amaranthus esculantus). Plant. Foods Hum. Nutr. 1993, 44, 63-70. [CrossRef] [PubMed]

23. Qureshi, A.A.; Lehmann, J.W.; Peterson, D.M. Amaranth and its oil inhibit cholesterol biosynthesis in 6-week-old female chickens. J. Nutr. 1996, 126, 1972-1978. [PubMed]

24. Berger, A.; Gremaud, G.; Baumgartner, M.; Rein, D.; Monnard, I.; Kratky, E.; Geiger, W.; Burri, J.; Dionisi, F.; Allan, M.; et al. Cholesterol-lowering properties of amaranth grain and oil in hamsters. Int. J. Vitam. Nutr. Res. 2003, 73, 39-47. [CrossRef] [PubMed]

25. Martirosyan, D.M.; Miroshnichenko, L.A.; Kulakova, S.N.; Pogojeva, A.V.; Zoloedov, V.I. Amaranth oil application for coronary heart disease and hypertension. Lipids Health Dis. 2007, 6, 1. [CrossRef]

26. De Castro, L.I.A.; Soares, R.A.M.; Saldiva, P.H.N.; Ferrari, R.A.; Miguel, A.M.R.O.; Almeida, C.A.S.; Arêas, J.A.G. Amaranth oil increased fecal excretion of bile Acid but had no effect in reducing plasma cholesterol in hamsters. Lipids 2013, 48, 609-618. [CrossRef]

27. Miettinen, T.A.; Vanhanen, H. Serum concentration and metabolism of cholesterol during rapeseed oil and squalene feeding. Am. J. Clin. Nutr. 1994, 59, 356-363. [CrossRef] 
28. Fattore, E.; Fanelli, R. Palm oil and palmitic acid: A review on cardiovascular effects and carcinogenicity. Int. J. Food Sci. Nutr. 2013, 64, 648-659. [CrossRef]

29. Clandinin, M.T.; Cook, S.L.; Konard, S.D.; French, M.A. The effect of palmitic acid on lipoprotein cholesterol levels. Int. J. Food Sci. Nutr. 2000, 51, S61-S71. [CrossRef]

30. Fernández-Macías, J.C.; Ochoa-Martínez, A.C.; Varela-Silva, J.A.; Pérez-Maldonado, I.N. Atherogenic Index of Plasma: Novel Predictive Biomarker for Cardiovascular Illnesses. Arch. Med. Res. 2019, 50, 285-294. [CrossRef]

31. Dobiásová, M. AIP-atherogenic index of plasma as a significant predictor of cardiovascular risk: From research to practice. Vnitr. Lek. 2006, 52, 64-71. [PubMed]

32. Edwards, M.K.; Blaha, M.J.; Loprinzi, P.D. Atherogenic Index of Plasma and Triglyceride/High-Density Lipoprotein Cholesterol Ratio Predict Mortality Risk Better Than Individual Cholesterol Risk Factors, Among an Older Adult Population. Mayo Clin. Proc. 2017, 92, 680-681. [CrossRef] [PubMed]

33. Lankinen, M.A.; Fauland, A.; Shimizu, B.-I.; Ågren, J.; Wheelock, C.E.; Laakso, M.; Schwab, U.; Pihlajamäki, J. Inflammatory response to dietary linoleic acid depends on FADS1 genotype. Am. J. Clin. Nutr. 2019, 109, 165-175. [CrossRef] [PubMed]

34. Duś-Żuchowska, M.; Bajerska, J.; Krzyżanowska, P.; Chmurzyńska, A.; Miśkiewicz-Chotnicka, A.; Muzsik, A.; Walkowiak, J. The Central European diet as an alternative to the Mediterranean diet in atherosclerosis prevention in postmenopausal obese women with a high risk of metabolic syndrome-a randomized nutrition-al trial. Acta Sci. Pol. Technol. Aliment. 2018, 17, 399-407. [PubMed]

35. Sarker, U.; Oba, S. Drought stress enhances nutritional and bioactive compounds, phenolic acids and antioxidant capacity of Amaranthus leafy vegetable. BMC Plant. Biol. 2018, 18, 258. [CrossRef] [PubMed]

(C) 2019 by the authors. Licensee MDPI, Basel, Switzerland. This article is an open access article distributed under the terms and conditions of the Creative Commons Attribution (CC BY) license (http://creativecommons.org/licenses/by/4.0/). 